\title{
EFEKTIVITAS MODEL PROBLEM BASED LEARNING DALAM MENINGKATKAN KEMAMPUAN BERPIKIR KRITIS PESERTA DIDIK PADA KELAS BISNIS DAN KEWIRAUSAHAAN
}

\author{
Intan Putri Thahara \\ Universitas Pendidikan Indonesia \\ Putri.intan@student.upi.edu \\ Hari Mulyadi \\ Universitas Pendidikan Indonesia \\ Harimulyadi@upi.edu \\ Rd. Dian H. Utama \\ Universitas Pendidikan Indonesia \\ Dhutama@upi.edu
}

\begin{abstract}
Tujuan - untuk mengetahui efektivitas model implementasi pembelajaran berbasis masalah pada keterampilan berpikir kritis siswa.

Desain/metodologi/pendekatan - metode eksperimen dengan bentuk quasi eksperimental.populasi penelitian ini adalah peserta didik kelas XI Pemasaran. Data dilakukan dengan tes tertulis kemampuan berpikir kritis dan kuisioner. Analisis data dilakukan dengan uji t (paired sample t-test), independent sample t test, dan uji analisis ANOVA dua arah.

Temuan Penelitian - peningkatan keterampilan berpikir kritis dengan pengobatan PBL.

Orisinalitas/nilai - memberikan dasar untuk memahami isu-isu mahasiswa berpikir kritis pada impementasi PBL. Perbedaan penelitian ini dengan penelitian sebelumnya pada kelas control dan eksperimen, variabel yang digunakan, mendukung teori serta referensi yang berbeda yang digunakan oleh peneliti sebelumnya.

Kata kunci: PBL, Problem Based Learning, Berpikir Kritis, Orde Berpikir Tinggi, Efektivitas PBL pada siswa keterampilan berpikir kritis, PBL untuk meningkatkan siswa keterampilan berpikir kritis
\end{abstract}

Jenis Penelitian: Jurnal Penelitian

\section{PENDAHULUAN}

Perkembangan teknologi memberikan banyak pengaruh pada berbagai bidang, salah satu bidang yang mengalami kemajuan dengan adanya teknologi adalah bidang pendidikan. UNESCO tujuan pendidikan dunia adalah dalam upaya meningkatkan kualitas suatu bangsa, tidak ada cara lain kecuali melalui peningkatan mutu pendidikan. Berangkat dari pemikiran itu, Perserikatan Bangsa-Bangsa (PBB) melalui lembaga UNESCO (United Nations, Educational, Scientific and Cultural Organization) mencanangkan empat pilar pendidikan baik untuk masa sekarang maupun masa depan, yakni 1) learning to know; 2) learning to do; 3) learning to be, dan ; 4) learning to live together. Dimana keempat pilar pendidikan tersebut menggabungkan tujuan-tujuan IQ, EQ dan SQ. Sesuai dengan pernyataan tersebut, tujuan pendidikan Indonesia menurut UUD 1945 tentang pendidikan dituangkan dalam Undang-Undang No. 20, Tahun 2003. Pasal 3 menyebutkan, "Pendidikan nasional berfungsi mengembangkan kemampuan dan membentuk watak serta peradaban bangsa yang bermartabat dalam rangka mencerdaskan kehidupan bangsa, bertujuan untuk berkembangnya potensi peserta didik agar menjadi manusia yang beriman dan bertakwa kepada Tuhan Yang Maha Esa, berakhlak mulia, sehat, berilmu, cakap, kreatif, mandiri, dan menjadi warga negara yang demokratis serta bertanggung jawab."

Perguruan Tinggi merupakan pelaksana pendidikan sekaligus ujung tombak pelaksana tujuan pendidikan. (Lena Nuryanti, 2004). Salah satu isu penting yang banyak dikaji pada bidang manajemen pemasaran adalah rendahnya berpikir kritis di era kompetitif ini masih menjadi isu utama dalam bidang pendidikan. Berpikir kritis dibutuhkan sepanjang hidup seseorang serta dapat berkontribusi secara kreatif dalam proses belajar maupun karir seseorang tersebut (Aizikovitsh-udi \& Cheng, 2015).

Kemampuan berpikir kritis dianggap penting bagi peserta didik untuk menghadapi banyak tantangan hidup dewasa dan berfungsi secara efektif dalam dunia yang semakin kompleks Nickerson (Dawit T. Tiruneh, 2014). Berpikir kritis atau critical thinking (CT) adalah atribut penting dalam perkembangan intelektual, akuisisi pengetahuan, dan pemanfaatan pengetahuan dalam individu, guru diharapkan 
untuk memelihara keterampilan berpikir kritis siswa (Gul et al., 2014). Berpikir kritis merupakan topik penting dalam pendidikan dan pengembangan keterampilan berpikir kritis harus menjadi salah satu tujuan utama bagi para pendidik di semua tingkatan (Sharadgah, 2014). Berpikir kritis termasuk dalam kemampuan berpikir tingkat tinggi dan diyakini dapat mempersiapkan peserta didik untuk menghadapi tantangan pekerjaan serta kehidupan sehari-hari (Ramos, Crosnoe, \& Muller, 2013). Mengatasi kesenjangan dalam pendidikan, yang berarti memfasilitasi keterampilan berpikir kritis, tujuan pengajaran harus peduli dengan mendorong peserta didik untuk menjadi reseptif, perseptif, reflektif, kritis, dan mempertanyakan inkonsistensi dalam pelajaran yang disajikan (Brien, 2013). Penting bagi guru untuk meningkatkan berpikir kritis untuk perkembangan intelektual, pengembangan diri dan pemanfaatan pengetahuan keterampilan, komunikasi kecepatan tinggi, karena perubahan yang cepat dalam kehidupan global. (Tiruneh, Verburgh, \& Elen, 2014) Rendahnya kemampuan berpikir kritis peserta didik dikarenakan model pembelajaran yang diterapkan di kelas belum efektif untuk meningkatkan kemampuan berpikir kritis. Anderson, Lorin W. \& Krathwohl, David R. (2001) mengelompokkan tujuan pendidikan taksonomi bloom yaitu kognitif, afektif dan psikomotor, berpikir kritis berada ranah kognitif.

Inti dari mengklarifikasi masalah dan mengidentifikasi konsep pada tahap ini adalah untuk memfasilitasi hubungan antara konsepkonsep dan isu atau masalah yang telah dimiliki oleh siswa dengan informasi baru yang akan diajarkan. Upaya ini awal penggalian konsep dalam konteks ini sangat penting untuk pembelajaran siswa kondisi kesiapan (Hurriyati, Lisnawati, Sulastri, \& Romansyah, 2016). Kemajuan suatu perusahaan ditentukan oleh kualitas sumber daya manusia yang dimilikinya, sehingga sangatlah penting bagi suatu perusahaa untuk memperhatikan kualitas sumber daya manusia yang dalam hal ini adalah karyawannya (Senen, Hadi Syamsul dan Solihat, 2013).

Salah satu dari lembaga pendidikan tersebut adalah Sekolah Menengah Kejuruan (SMK). Sekolah Menengah Kejuruan adalah jenjang pendidikan menengah formal yang kurikulumnya mengacu pada pendekatan akan kebutuhan dunia usaha dan dunia industri (DU/DI). Pendidikan kejuruan dinilai sebagai solusi praktis mengurangi jumlah pengangguran. Selain itu, pendidikan kejuruan juga dinilai strategis dalam meningkatkan kualitas sumber daya manusia (SDM) Indonesia. (Masharyono, 2009) Penelitian berada di Bandung. dianggap memiliki keunikan dalam memberikan atmosfir yang berbeda dengan daerah wisata lainnya. Dengan demikian, wisatawan percaya bahwa mereka dapat memperoleh penyegaran (refresh) setelah mereka mengadakan liburan di Bandung (Lili Adi Wibowo \& Yuniawati, 2007).

\section{KAJIAN PUSTAKA}

PBL merupakan model pembelajaran yang dapat digunakan untuk struktur pembangunan di tingkat kurikulum dengan menempatkan siswa dalam peran aktif dari pemecah masalah yang menyerupai masalah di dunia nyata (Savery, 2006). Meskipun ada perbedaan dalam cara model berbasis masalah dipraktekkan di seluruh dunia, mereka didirikan atas dasar teoritis yang sama dan dengan demikian memiliki prinsip yang sama belajar. Referensi sering dibuat untuk yang konstruktivis awal yaitu dari Bruner (1966) yang bekerja terkait dengan penelitian perkembangan anak (terutama Piaget). Teori konstruktivis mendukung bahwa orang belajar terbaik ketika mereka secara aktif membangun sendiri pemahaman. Diikuti oleh teori yang lebih baru, antara lain Kolb (1984), Lave dan Wenger (1991) dan Gardner (1993). Semua teori ini melihat bahwa tangan-pengalaman yang sama-untukhidup diperoleh dari kelas kegiatan merupakan pendekatan penting untuk proses lebih lanjut dari motivasi dan belajar (Dagyar \& Demirel, 2015). Perlakuan PBL dilakukan oleh guru, sebagaimana guru memiliki kompetensi pedagogik, kepribadian, sosial dan professional .(Surachim, 2013)

Berpikir kritis (CT) adalah atribut penting dalam perkembangan intelektual, akuisisi pengetahuan, dan pemanfaatan pengetahuan dalam individu, guru diharapkan untuk memelihara keterampilan berpikir kritis siswa (Gul et al., 2014) Ini diasumsikan bahwa guru tahu apa CT dan bagaimana hal itu dapat dipromosikan di praktek mengajar mereka, tetapi ini tidak mungkin benar (Jafarigohar, 2016) kecuali mereka memiliki belajar di pra-layanan mereka atau in-service training (Kong,2006). Guru sebagai pemberi pengetahuan daripada fasilitator pengembangan pengetahuan siswa (Gul et al., 2014) Guru harus meniru CT jika mereka berharap siswa mereka untuk melakukannya. Untuk mempromosikan CT siswa, guru harus memilih konten yang sesuai dan strategi pembelajaran untuk mengatasi tujuan pembelajaran, dan mereka harus memfasilitasi teacherstudent interaksi, mendorong siswa untuk bertanya, dan menanggapi pertanyaan mereka tanpa prasangka (Gul et al., 2014) 
Gambar 1 Paradigma Penelitian

\begin{tabular}{|c|c|}
\hline 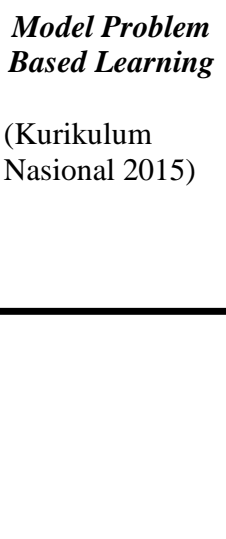 & $\begin{array}{ll}\text { Berpikir Kritis } \\
\text { 1. } \\
\text { 2. } & \text { Mlarifikasi dasar } \\
& \text { dasar sumber } \\
\text { 3. } & \begin{array}{l}\text { Membuat } \\
\text { kesimpulan }\end{array} \\
\text { 4. } & \text { Melakukan } \\
& \text { klarifikasi tingkat } \\
& \text { lanjut } \\
\text { 5. } & \text { Menerapkan } \\
\text { strategi dan taktik } \\
\text { dalam } \\
\text { menyelesikan } \\
\text { masalah }\end{array}$ \\
\hline & $\begin{array}{l}\text { (Nitko \& Brookhart } \\
(2011: 234-236)\end{array}$ \\
\hline
\end{tabular}

\section{METODE PENELITIAN}

Penelitian ini menganalisis mengenai pengaruh problem based learning terhadap peningkatan kemampuan berpikir kritis pada mata pelajaran prakarya dan kewirausahaan di SMKN 11 Bandung. Penelitian sebagai variabel bebas (independent variable) yaitu Problem Based Learning yang memiliki dimensi dasar yaitu, pengetahuan faktual, konseptual, prosedural, proses kognitif data masalah penelitian yang merupakan variabel terikat (dependent variable) yaitu kemampuan berpikir kritis memiliki dimensi dasar yaitu klarifikasi dasar, menilai dukungan dasar sumber, Membuat kesimpulan, melakukan klarifikasi tingkat lanjut, menerapkan strategi dan taktik dalam menyelesikan masalah.

Objek/unit analisis pada penelitian ini yaitu siswa peserta didik kelas XI pemasaran SMKN 11 Bandung. Penelitian ini dilakukan pada kurun waktu kurang dari satu tahun, sehingga teknik pengumpulan data yang digunakan pada penelitian ini adalah cross-sectional method. Teknik yang digunakan dalam penelitian ini adalah teknik sampling jenuh dengan jumlah sampel sebanyak 63 konsumen. Teknik pengumpulan data yang digunakan adalah studi kepustakaan, studi lapangan dengan penyebaran kuesioner secara online, tes kemampuan berpikir kritis dan studi literatur. Sedangkan teknik analisis data yang dilakukan adalah analisis deskriptif dan verifikatif. Analisis data verifikatif menggunakan t-test dan effect size analysis dengan bantuan software SPSS 20.0 for windows.

\section{HASIL PENELITIAN DAN PEMBAHASAN}

Pengujian hipotesis pada penelitian ini dilakukan untuk mengetahui besarnya pengaruh PBL terhadap peningkatan kemampuan berpikir kritis. Hipotesis penelitian ini adalah PBL berpengaruh secara positif terhadap peningkatan kemampuan berpikir kritis. Hasil pengujian hipotesis secara keseluruhan dapat dilihat berdasarkan tabel anova dengan nilai $t_{\text {hitung }}$ sebesar 79,495 dan $t_{\text {tabel }} 1.670$, hasil tersebut menunjukkan bahwa $t_{\text {hitung }}(0,241)<0,05$ maka dapat diambil keputusan bahwa hipotesis nol $\left(\mathrm{H}_{0}\right)$ ditolak dan $\mathrm{H}_{\mathrm{i}}$ diterima, sehingga dapat dikatakan bahwa terdapat pengaruh antara PBL terhadap kemampuan berpikir kritis. Hasil tersebut juga menunjukkan bahwa model regresi yang digunakan sudah layak dan benar. Uji angka probabilitas (Sig) menunjukkan hasil bahwa nilai tingkat probabilitas $(\mathrm{Sig})=0,000$, karena nilai Sig $(0,000) \leq 0,05$ maka keputusannya adalah $\mathrm{H}_{0}$ ditolak dan $\mathrm{H}_{\mathrm{i}}$ diterima, hal tersebut memberikan arti bahwa terdapat pengaruh antara PBL terhadap kemampuan berpikir kritis.

Pembahasan mengenai peningkatan kelas eksperimen yang menggunakan PBL, pada kelas eksperimen yang berjumlah 30 peserta didik menunjukkan peningkatan kemampuan berpikir kritis. Pada tes awal dan tes akhir terjadi peningkatan nilai minimum 4 atau $66.67 \%$ dari nilai minimum tes awal sebesar 6 menjadi 10 pada tes akhir. Peningkatan terjadi pada skor maksimum dengan peningkatan sebesar 12 atau $60 \%$ dari skor maksimum tes awal sebesar 20 menjadi 32 pada tes akhir. Nilai rata-rata pada tes awal adalah 11,93 sedangkan pada tes akhir menjadi 19,62. Terjadi Peningkatan sebesar 7,69 atau $64.45 \%$.

Pembahasan mengenai peningkatan kelas eksperimen yang menggunakan ceramah, pada kelas kontrol yang berjumlah 33 peserta didik menunjukkan peningkatan kemampuan berpikir kritis. Pada tes awal dan tes akhir terjadi peningkatan nilai minimum 3 atau $50 \%$ dari nilai minimum tes awal sebesar 6 menjadi 9 pada tes akhir. Peningkatan terjadi pada skor maksimum dengan peningkatan sebesar 6 atau 28,57\% dari skor maksimum tes awal sebesar 21 menjadi 27 pada tes akhir. Nilai rata-rata pada tes awal adalah 11,60 sedangkan pada tes akhir menjadi 15,62. Terjadi peningkatan sebesar 4,02 atau 34,65\%.

Hasil $N$-Gain ternormalisasi maka dapat terlihat perbandingan gain nilai yang sudah ternormalisasi $\langle\mathrm{g}>$ antara kelas eksperimen dan kelas control. Rata-rata kelas eksperimen yang bernilai 0,75. Pada kelas eksperimen dari total jumlah 30 orang, 4 orang diantaranya memperoleh kriteria $\langle\mathrm{g}\rangle$ rendah, 11 orang diantaranya memperoleh kriteria $\langle\mathrm{g}\rangle$ sedang dan 15 orang diantaranya memperoleh kriteria $\langle\mathrm{g}\rangle$ tinggi. Rata-rata kelas kontrol yang bernilai 0,41 . Kelas kontrol memiliki jumlah peserta didik sebanyak 33 orang. Dari 33 orang, 12 orang diantaranya memperoleh kriteria $\langle\mathrm{g}\rangle$ rendah, sebanyak 18 orang diantaranya memperoleh 
kriteria $\langle\mathrm{g}\rangle$ sedang, dan 3 orang diantaranya memperoleh kriteria $\langle\mathrm{g}\rangle$ tinggi.

Berdasarkan penjelasan tersebut konsep indikator model pembelajaran Problem Based Learning (PBL) yang digunakan dalam penelitian ini mengadopsi dan memodifikasi teori serta konsep yang berasal dari (Rusmono 2014:89) "Model pembelajaran Problem Based Learning (PBL) terdiri dari dua elemen utama, yaitu pengetahuan yang meliputi faktual, konseptual, dan prosedural. Selanjutnya elemen proses kognitif meliputi ingatan, pemahaman, penerapan dan analisis"

Kemampuan Berpikir kritis Fischer (2009:3) Berpikir kritis menuntut upaya keras untuk memeriksa keyakinan atau asumsi berdasarkan bukti pendukung dan kesimpulan-kesimpulan lanjutan yang ditimbulkannya.

Pengaruh Model Pembelajaran Problem Based Learning (PBL) terhadap kemampuan berpikir kritis

Berdasarkan penelitian, ditemukan teoritis yaitu berupa kaitan atau pengaruh model pembelajaran Problem Based Learning (PBL) terhadap kemampuan berpikir kritis yang didukung oleh beberapa teori seperti yang dikemukakan oleh Buang Saryantono (2013:3) yang mengemukakan bahwa: Model PBL digunakan untuk merangsang berfikir tingkat tinggi dengan situasi berorientasi pada masalah, termasuk didalamnya belajar bagaimana cara belajar. Peran guru dalam model PBL adalah menyajikan masalah, mengajukan pertanyaan dan dialog. Model PBL tidak dapat dilaksanakan tanpa guru mengembangkan lingkungan kelas yang memungkinkan terjadinya pertukaran ide secara terbuka. Selain itu rata-rata hasil belajar yang menggunakan PBL lebih tinggi dibandingkan dengan model pembelajaran konvensional. Hal tersebut memiliki pengaruh positif terhadap hasil belajar peserta didik yang akan mereka kembangkan kedalam kehidupan sehari-hari.

\section{KESIMPULAN \& REKOMENDASI}

Berdasarkan hasil penelitian yang telah dilakukan menggunakan analisis uji $\mathrm{t}$ dan normalisasi gain dengan effect size dapat diambil kesimpulan bahwa PBL berpengaruh positif terhadap peningkatan kemampuan berpikir kritis.

Penelitian ini diharapkan dapat membantu bagi lembaga pendidikan dan guru dapat lebih memperhatikan kemampuan berpikir kritis.

\section{DAFTAR PUSTAKA}

Aizikovitsh-udi, E., \& Cheng, D. (2015). Developing Critical Thinking Skills from Dispositions to Abilities: Mathematics Education from Early Childhood to High.
Creative Education, 6(March), 455-462

Brien, T. L. (2013). AR: The Development of CT Skills.

Dagyar, M., \& Demirel, M. (2015). Effects of problem-based learning on academic achievement: A meta-analysis study. Egitim ve Bilim, 40(181), 139-174. http://doi.org/10.15390/EB.2015.4429

Gul, R. B., Khan, S., Ahmed, A., Cassum, S., Saeed, T., Parpio, Y., \& Profetto-mcgrath, J. (2014). Enhancing Educators' Skills for Promoting Critical Thinking in Their Classroom Discourses: A Randomized Control Trial. International Journal of Teaching and Learning in Higher Education, 26(1), 37-54. Retrieved from http://www.isetl.org/ijtlhe/

Hurriyati, R., Lisnawati, Sulastri, \& Romansyah, Y. (2016). Learning Model of Entreupreuneurship Using Business Incubator Based on Web 2 . 0 Technology, (Icieve 2015), 22-25.

Jafarigohar, M. (2016). Instructors 'Attitudes towards the Reflection of Critical Thinking in Course Syllabi: Evidence from an Expanding Circle, 6(1), 59-67.

Lena Nuryanti. (2004). Model Pembelajaran ELearning Melalui Homepage Sebagai Media Pembelajaran Sehingga Diharapkan Dapat Meningkatkan Minat Dan Kreativitas Siswa.

Lili Adi Wibowo, \& Yuniawati, Y. (2007). The Influence of Tourist Product Attribute and Trust to Tourist Satisfaction and Loyalty A Study of Mini Vacation in Bandung. UPI, 53(9), 1689-1699. http://doi.org/10.1017/CBO9781107415324 .004

Masharyono. (2009). Peran pendidikan dan pemberdayaan ekonomi keluarga, 95-102.

Ramos, A. I., Crosnoe, R., \& Muller, C. (2013). The Preschool and Kindergarten Classrooms of Children from Latino / a Language Minority Families.

Savery, J. R. (2006). Overview of Problem-based Learning: Definitions and Distinctions. Interdisciplinary Journal of Problem-Based Learning, $1(1)$, 13. http://doi.org/10.7771/1541-5015.1002

Senen, Hadi Syamsul dan Solihat, S. (2013). Terhadap Produktivitas Kerja Karyawan Pada, 7(September), 1-15.

Sharadgah, T. A. Al. (2014). Developing Critical Thinking Skills through Writing in an Internet-Based Environment. International Journal of Humanities and Social Science, 4(1), 169-178.

Surachim, A. (2013). Dual Education System ( PSG ) Effectiveness to Improving SMK 
Journal of Business Management Education | Volume 1, Number 2, August 2016, page. 70-74

Graduates Quality, 2(323).

Tiruneh, D. T., Verburgh, A., \& Elen, J. (2014).

Effectiveness of Critical Thinking

Instruction in Higher Education: A
Systematic Review of Intervention Studies. Higher Education Studies, 4(1), 1-17. http://doi.org/10.5539/hes.v4n1p1 